\title{
Romanya'nın Eski Kraliyet Döneminde Osmanlı Diplomatları ve Osmanlı Topluluğu: 1878-1908 Yılları Arasında Osmanlı-Rumen İlişkileri
}

\section{Ottoman Diplomats and Turkish Community in the Romania Old Kingdom: Ottoman-Romanian Relations between 1878 and 1908}

Silvana Rachieru, Diplomați și Supuși Otomani în Vechiul Regat: Relații Otomano-Române între Anii 1878 și 1908, lași: Editura Universității “Al. I. Cuza”, 2018, 291 p., ISBN: 978-606-714-425-3.

Mariana Budu' (1)

'Sorumlu yazar/Corresponding author: Mariana Budu (Öğr. Gör. Dr.),

Istanbul Üniversitesi, Edebiyat Fakültesi Slav Dilleri ve Edebiyatları Bölümü Leh Dili ve Edebiyatı Anabilim Dalı, İstanbul, Türkiye. E-posta: mariana.budu@istanbul.edu.tr ORCID: 0000-0001-9000-4029

Bașvuru/Submitted: 10.09.2020

Kabul/Accepted: 12.12 .2020

Atıf/Citation: Budu, Mariana, "Romanya'nın Eski Kraliyet Döneminde Osmanlı Diplomatları ve Osmanlı Topluluğu: 1878-1908 Yılları Arasında Osmanlı-Rumen Illişkileri" (Kitabiyat). Güney-Doğu Avrupa Araştırmaları Dergisi, 35 (2020), s. 207-212

https://doi.org/10.26650/gaad.165627

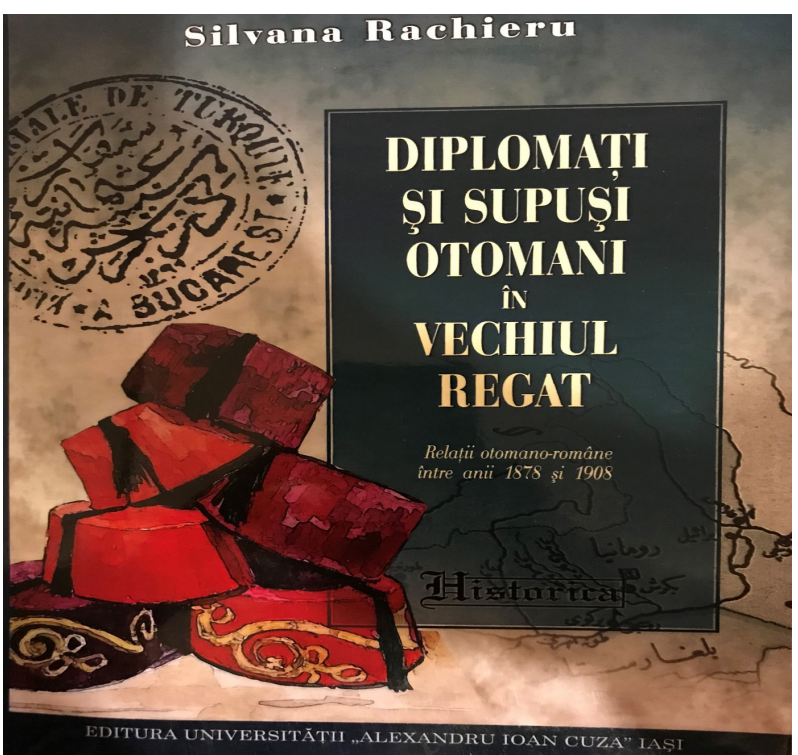

Anahtar Kelimeler: Rachieru, Romanya, Osmanlı Imparatorluğu, Osmanlı Diplomatları, Osmanlı-Rumen Illişkileri, Modernleşme

Keywords: Rachieru, Romania, Ottoman Empire, Ottoman Diplomats, Ottoman-Romanian Relations, Modernization 
Silvana Rachieru, Osmanlı Devleti ve Romanya ilişkilerinin tarihi üzerine çalışmalar yapan, önde gelen çağdaş Rumen mütehassıslardan birisidir. Rachieru, 2010 yılında Bükreş Üniversitesi Tarih Bölümü'nde Osmanlı-Rumen İlişkileri: 1878-1908 başlıklı tez ile doktorasını tamamlamıştır. Hâlen Bükreş Üniversitesi Tarih Bölümü’nde doçent olarak görev yapmaktadır. Osmanlı Devleti ve Romanya diplomatik ilişkileri, Romanya'nın modernleşmesi üzerine Osmanlı bakış açısı, Osmanlı tarihi, 19. yüzyılın Osmanlı-Rumen ilişkileri ve cinsiyet araştırmaları üzerine otuzdan fazla çalışmaya sahip olan Doç. Dr. Silvana Rachieru, 2018 yılında Romanya'nın Eski Kraliyet Döneminde Osmanlı Diplomatları ve Osmanlı Topluluğu: 1878-1908 Yılları Arasında Osmanlı-Rumen Iliş̧kileri başlıklı kitabını yayımlamıştır. Kitap büyük ölçüde yazarın Osmanlı-Rumen Ilişkileri: 1878-1908 konulu doktora tezine dayanmaktadır.

Çalışmada Berlin Antlaşması (1878) sonucu bağımsızlığının tanınmasının ardından Romanya ile Osmanlı Devleti arasında gelişen diplomatik ilişkilerin gidişatı geniş bir bakış açısıyla incelenmiştir. 19. yüzyılın ikinci yarısından sonra Osmanlı diplomasisi Avrupa sistemine katılmıştır. Bu süreç, Hariciye Nezâreti'nin II. Abdülhamid döneminde daha önce görülmemiş yüksek profesyonellik seviyesine ulaşması ile sonuçlanmıştır. Osmanlı diplomatik sisteminin modernleşmesi ve profesyonelleşmesi, 1878'den sonra Osmanlı-Romanya ilişkilerini oldukça etkilemiştir. Osmanlı Devleti'ni temsil etmek üzere gönderilen diplomatların, sistemin gelişmesine katkı sağladıkları kabul edilmektedir. Romanya'ya gelen temsilciler yerel diplomatik unsurlarla iyi bir şekilde entegre olmuştur. Osmanlı temsilcileri, 38 yıl devam eden diplomatik ilişkiler süresince misyonun gerektirdiği şekilde Romanya hakkında ayrıntılı raporlar sunmuştur. Bu raporların incelenmesi ve analiz edilmesi kitabın ana konusunu oluşturmaktadır.

Yazar, 38 yılı kapsayan Osmanlı dış temsilciliği arşivindeki yazışmaları, Rumen Dışişleri Bakanlığı'nın arşivini, Archives Diplomatiques de Nantes'ın yanında konu ile ilgili yapılan Türkçe, Rumence, Fransızca ve İngilizce çalışmaları etüt etmektedir.

Romanya'nın Eski Kraliyet Döneminde Osmanlı Diplomatları ve Osmanlı Topluluğu: 1878-1908 Yılları Arasında Osmanlı-Rumen İlişkileri adlı eser 291 sayfadan ibaret olup giriş, beş bölüm, sonuç, ekler, kaynakça, geniş İngilizce özet ve indeks şeklinde düzenlenmiştir.

Giriş (ss. 9-28) kısmında, araştırmanın kaynaklarından bahsedilmektedir. Yazar konu ile ilgili Türkiye'de Başbakanlık Osmanlı Arşivi'nde bulunan Hariciye Nezareti Evrakı (hukuk, siyasî ve mütenevvia kısmı), Romanya'daki Dışişleri Bakanlık Arşivi ve Merkezi Ulusal Tarih Arşivleri'nde bulunan katalogları ve Fransa'daki Archives Diplomatiques de Nantes'te bulunan katalogları tanıtmıştır. İncelenen katalogların, kitabın hangi bölümde kullanıldığı da belirtilmiştir. Osmanlı Devleti'nin son dönemini çalışan Bernard Lewis, Șerif Mardin, Roderic Davison, Niyazi Berkes, Illber Ortaylı, Donald Quataert, Selçuk Akşin Somel, Oliver Bouquet gibi önemli yazarların görüşlerine de yer verilmiştir. Yazar bu kısımda ayrıca çalışmada kullandığı metodolojiden detaylı olarak bahsetmiştir. 
Modernizarea Sistemului Diplomatic Otoman și Influența Sa Asupra Relațiilor Otomano-Române După 1878 [Osmanlı Imparatorluğu'nun Diplomatik Yapısının Modernleşmesi ve 1878 Sonrası Rumen ilişkilerine Etkisi] (ss. 29-58) şeklinde adlandırılan birinci bölümde, 18781916 yılların arasında padişah temsilcilerinin Romanya'ya gönderdikleri diplomatik raporlar kaynakça olarak kullanılmıştır. Yazar, kitabın bu bölümünü üç alt bölüm altında incelemiştir. Ilk olarak (Umur-ı) Hariciye Nezareti'nin kuruluş öncesi Osmanlı dış diplomasisinden kısaca bahsedilmiştir. Devamında Hariciye Nezareti'nin ve Tercüme Odası'nın kuruluşu, yapısı ve fonksiyonları incelenmiştir. Yazar, Hariciye Nezareti'nin yapısını incelerken Carter V. Findley'nin Bureaucratic Reform in the Ottoman Empire. The Sublime Porte, 1789-1922 adlı çalışmada oluşturduğu şemayı kullanmıştır. Findley'in şemasına ilaveten, yazar bazı kronolojik detaylar ekleyerek çalısmasına uygun bir formt oluşturmuştur. Bu şekilde Hariciye Nezareti'nin yapısında yer alan (Osmanlı bürokratları) diplomatlar, konsolosluklar, büyükelçiler ile ilgili detaylı bilgiler vermektedir. Yazar, bunların ilk göreve başladıklarında yaş, etnik ve dini profili, görevlerin süresi ve diplomasideki faaliyetlerinin süresini incelemektedir. Bu kısımda yazar aynı zamanda Sinan Kuneralp'in, Son Dönem Osmanlı Erkân ve Recali (1839-1922. Prosopografik Rehber çalışmasını da kaynak olarak kullanmıştır. Buna ilâveten Başbakanlık Osmanlı Arşivi ve Romanya'daki arşivlerde elde ettiği belgeleri kullanmıştır. Yazar bu bölüm içinde Osmanlı dış diplomasisinin modernleşmesine katkısı olan telgraftan da bahsetmektedir. Sonuç olarak yazar III. Selim dönemindeki modernleşmeye yönelik ilk inisiyatifleri ve bu inisiyatiflerin gerçekleştirilememesinin nedenlerini analiz etmiştir.

Reprezentanță Diplomatică Otomană în România [Romanya'da Osmanlı Diplomatik Temsili] (ss. 59-107) adlı ikinci bölüm, dört alt başılı altında incelenmektedir. Yazar, "Osmanlı Elçileri Bükreş'te" adlı alt başlıkı bölümde 1878-1916 yılları arasında Bükreş Elçiliğine atanan sekiz elçiyi (Süleyman Sabit Bey, Ahmet Ziyâ Bey, Mehmed Feridun Bey, Edouard Blak Bey, Mehmed Şemseddin Bey, Mustafa Reşid Bey, Hüseyin Kazım Bey, Abdüllatif Safa Bey) görev yaptıkları yıllara göre sırasıyla tanıtmıştır. Her bir diplomata dair görev süresi, yaş, eğitim, ailevi durum gibi detaylı bilgiler vermiştir. Yazar, Romanya'ya gönderilen Osmanlı diplomatlarının iyi yetişmiş, yabancı dil bilen, II. Abdülhamid döneminin bürokratik geleneğe sahip elit tabakadan gelen kişiler oldukları sonucuna varmıştır. İkinci alt bölümde yazar, Osmanlı Elçiliğinin Bükreş'teki adresi ve elçilikte çalışmış olan heyetlerden bahsetmektedir. Üçüncü alt bölümde, Romanya'daki konsoloslar ve viskonsüller hakkında bilgi verilmektedir. Böylece, 1879-1916 yılları arasında Romanya'da bulunan yedi konsolos (Bükreş, Köstence, Brail, Galati, Yaş, Turnu Severin, Craiova) ve beş viskonsül (Tulça, Sulina, Yergöğü, Kalafat, Deliorman) hakkında detaylı bilgiler verilmiştir. Osmanlı diplomatların modelini çizen yazar, elçilerin büyük çoğunluğunun Müslüman, konsolosların ise sadece \%59'unun Müslüman olmasını Babıâli'nin Hariciye Nezareti'ndeki Osmanlııılık politikasının bir uygulaması olduğunu öne sürmektedir. Yazar, genellikle heyetlerin uzun süre kalmaları (2-12 yıl arası) elçilerin ülkenin yerel meselelerini ve dilini öğrenmelerine olanak sağlandığını da vurgulamıştır. Kadroların, 
genç ve kariyerinin başlangıcında bulunan ya da İstanbul'dan "personae non gratae" olarak sürgüne gönderilmiş memurlar olduklarını da tespit etmiştir. Yazar, elçilerin ilettiği belgeleri inceleyerek Osmanlı yetkililerinin savaş öncesi hükümdar-vasal yaklaşımıyla dönem itibarıyla bağımsız Romanya ile temaslarını değerlendirmiştir. Bu amaçla, Bükreş’te görevde bulunan büyükelçiler İstanbul'a göndermiş oldukları raporlarında yeni statü ile güncel ve yürürlükteki yasaları zaman zaman açıklamıştır.

“Görev Değişikliği” adlı dördüncü alt başlıkta, Osmanlı büyükelçilerinin Rumen eliti ve Kral I. Carol ile münasebetleri, kariyerlerin tipi ve konsolosluğun idari ve iktisadi sorunları ele alınmaktadır. Osmanlı-Rus Savaşı ile başlayan ve Birinci Cihan Harbi ile sona eren dönemde Birinci Balkan Savaşı'nın (1912-1913) haricinde Babıâli ile Romanya arasındaki ilişkilerde ciddi bir kriz görülmediği de tespit edilmiştir.

Politică și Economie în România Modernă din Perspectivă Otomană [Modern Romanya'da Siyaset ve Ekonomiye Osmanlı Bakış Açısı] (ss. 109-141) adlı üçüncü bölümün birinci alt bölümünde yazar, Romanya-Osmanlı diplomatik ilişkilerin başlamasını incelemektedir. Berlin Anlaşması'ndan sonra Osmanlı Devleti'nde açılan ilk konsolosluklar ve Babıâli'de kabul edilen ilk diplomat Dimitrie Braiteanu hakkında bilgi verilmektedir. Ayrıca yazar, Osmanlı-Rus Savaşı ile başlayan ve Birinci Cihan Harbi ile sona eren dönemde, Birinci Balkan Savaşı'nın (19121913) haricinde Babıâli ile Romanya arasındaki ilişkilerde ciddi bir kriz görülmediğini de vurgulamaktadır. İkinci alt bölümde yazar Hariciye Nezâreti'nin belgelerine dayanarak 1881'de Romanya'da kraliyetin ilan edilmesi, yönetim değişmeleri, parlamenter demokrasinin krizleri, kralın siyasal yetkileri gibi sıklıkla işlenmiş meselelerin üzerinde durmaktadır.

Bölümün diğer kısmında ise ülkenin genel iktisadi, özellikle köylülerin durumu, 1907'deki Köylü İsyanı ve bu olayın Osmanlı tebaası üzerine etkilerinden bahsedilmektedir. Dobruca meselesi Osmanlı diplomatlarının faaliyetlerinde önemli bir yer teşkil etmektedir. Büyükelçiler, sürekli olarak idari ve adli yeni kanunları, vatandaşlık sorunları ile ilgili ve yeni rejime dair bilgileri İstanbul'a göndermektedirler. Ayrıca Kral I. Carol'un bölgede ülkenin birlik ve bütünlüğünü sağlayan ziyaretleri Osmanlı kaynaklarına dayandırılarak son alt bölümde detaylı olarak zikredilmektedir.

Convenții între Imperiul Otoman și România [Osmanlı Imparatorluğu ve Romanya Arasındaki Antlașmalar] (ss. 143-168) isimli dördüncü bölümde, iki ülke arasında 40 yıl içeresinde imzalanan iki anlaşma üzerinde durulmaktadır. Bu anlaşmalardan biri 1878'de Osmanlı savaş esirlerinin geri gönderilmesine dair sözleşme, diğeri ise 1887, 1897, 1901, 1907 yıllarında imzalanan ticari anlaşmalardır. Bu konularla ilgili yazar, BAO arşivinde bulunan HR.SYS. 1060/4 dosyası ve Romanya AMAE fond Constantinopol dosyasını incelemiştir. Yazarın edindiği bilgilere göre savaş sonrası Romanya'da 6000 Osmanlı esiri bulunmaktadır. Bu problemi görüşmek üzere, Nisan 1878 yılında sultan tarafından Romanya'ya Azaryan Efendi gönderilmiştir. Konu ile ilgili Romanya'da bir komisyon oluşturulmuştur. Esirlerin geri gönderilmesine karşı çıkılmamıştır, fakat Rumen temsilcilerin talep ettikleri esirlerin bakım masrafları Osmanlı Devleti'ni memnun etmediğinden bahsedilmektedir. 
“Ticari Anlaşmalar” alt bölümünde yazar, 1887 yılında imzalanan sözleşme ve daha sonra 1897, 1901, 1907 yıllarında yenilenen ticari sözleşmelerin detaylarından bahsetmektedir. Yazar, Azaryan Efendi'nin raporuna dayanarak, 1901 yılında yenilenen sözleşmenin kuralları ve bu sözleşmede yer alan, ihracatı yapılan ürünlerin (orijinal adlarla) listesine de yer vermektedir.

Comunitatea Otomană în România [Romanya'daki Osmanlı Topluluğu] (ss. 169-239) isimli beşinci bölümünün ilk kısmında, Romanya'nın bağımsızlığını kazanması, Osmanlı Devleti'nin Romanya'da sayısız diplomatik ilişkilerin varlığı ve konsoloslukların anlaşmalarının Osmanlı tebaasının korunmasına sebep olduğu belirtilmektedir. Bu kısımda yazar, Osmanlı Devleti'nin 19. yüzyılın ikinci yarısındaki “vatandaş-tebaa-i Osmanî” kavramlarını terminolojik ve tarihi açıdan analiz etmektedir. Devamında, Romanya'da ikamet eden Osmanlı tebaası ile ilgili ayrıntılı bilgiler verilmektedir. Söz konusu dönemde, Romanya'da ikamet eden ikinci en kalabalık yabancı toplumu olarak sayılmıştır. 1899 yılında ülkenin \%4'ünü oluşturdukları tespit edilmiştir. Bu toplumun en önemli özelliklerinden biri, yüksek oranda gayrimüslim (sadece \%19'u Müslüman), eril (\%77'i erkek) ve aktif (\%43'ü 20-30 yaşı arası) olmalarıdır (s. 195). Silvana Rachieru, Osmanlı tebaasının dini, cinsiyeti, eğitim seviyesi ve coğrafi yayılımını belirterek yararlı bir tablo oluşturmaktadır. Yazar, bu bölümde aynı zamanda kısaca Romanya'da ikamet eden Osmanlı tebaasının hakları hakkında kısaca bilgi vermektedir. Rachieru, Osmanlı tebaasının Romanya'da yaptıkları meslekler hakkında da yararlı bir tablo oluşturmuştur. 119 kişinin adları ve soyadları ile birlikte meslekleri ve ikamet ettikleri adresleri vermektedir. Yazarın tespitlerine göre en çok yapılan meslekler tüccarlık, bakkalcılık, lokantacılık, fırıncılık ve marangozluktur.

Romanya'daki Osmanlı tebaasının okur yazarlık durumuna da değinilmektedir. Yazar, yararlı bir tablo oluşturarak Moldova, Oltenia, Muntenia ve Dobruca'da yaşayan 7-15 ile kı/ erkek ve 15 yaş sonrası kadın/erkek okur yazar oranlarını göstermiştir. Sonuç olarak yazar, 15 yaş üstü kadınların okuma-yazma oranının \%30, 15 yaş üstü erkeklerin okuma yazma oranının ise \%44 olduğunu tespit etmiştir.

Yazar, Romanya'da ikamet eden Osmanlı tebaasının hukuki sorunlarını de ele almıştır. Yazar 1878-1916 yılları arasındaki diplomatik belgelere dayanarak Osmanlı tebaasının yaşadıkları adli sorunlarını bölümün ikinci kısmında açıklamaktadır. Özellikle, Dobruca bölgesinde görülen mülk ve miras, vatandaşlık, kimlik kartı (doğrulama veya satma), askerlik hizmeti gibi sorunlar dile getirilmektedir. 1907 Köylü İsyanı'nın Osmanlı tebaası üzerine etkisi, kaydedilmiş zararları ve tazminatlarından bahsedilmektedir. Yazara göre başlıca sorunlar şunlardır: a) gayrimenkul ve araziler; b) miras; c) askerlik hizmetleri; d) ailevi sorunlar ve e) kazalardır. Araştırmaya göre 19. yüzyılın ikinci yarısında İstanbul ve Karadeniz bölgelerinden işgücü alan Romanya'da, mütenevvi aile meseleleri (terk etme, boşanma) ile sonuçlanmaktadır (ss. 227-231).

Çalışmanın devamında Sonuç (ss. 241-245), Ekler (ss. 249-268), Kaynakça (ss. 269281), İngilizce özet (ss.283-287) ve İndeks (ss. 289-291) kısımları yer almaktadır. Kitapta 
yer alan çeşitli koleksiyon resimleri, grafikler, haritalar ve tablolar, metni zenginleştirmiş ve anlaşılır kılmıştır.

Silvana Rachieru, ciddi bir metodoloji ve kaynakları iyi kullanan bir yaklaşımla, daha önce çalışılmamış olan Osmanlı Devleti ve Rumen diplomatik ilişkileri çalışmasıyla önemli bir boşluğu doldurmuştur. Eser, bu alandaki hem Romanya hem Türkiye'deki çalışmalar için atılan önemli bir adım olarak nitelendirilebilir. Görülen o ki eser, Romanya'daki Osmanlı ve Türk araştırmalarının yeniden canlandırılmasına da katkı sağlayacaktır. 